\title{
Cervical Dysgenesis with Transverse Vaginal Septum with Imperforate Hymen in an 11 year old Girl Presenting with Acute Abdomen
}

\author{
Pratiksha Gupta, ${ }^{1}$ Sangeeta Gupta, ${ }^{1}$ Sunita Jindal, ${ }^{1}$ Kanwaljeet Chopra, ${ }^{2}$ Manjari Sinha, ${ }^{1}$ Anita Arora ${ }^{2}$ \\ 'Department of Gynaecology and Obstetrics, ${ }^{2}$ Department of Paediatrics, Post Graduate Institute of Medical Sciences and \\ Research, ESICH, Basaidarapur, New Delhi.
}

\section{ABSTRACT}

This case highlights the importance of careful evaluation of girls presenting with imperforate hymen as this is accompanied by other female reproductive tract anomalies. It is of utmost importance that a correct timely diagnosis is made so that the right treatment can be chosen with the perspective of future fertility. Cervical dysgenesis associated with vaginal septum and imperforate hymen has not been reported in literature so far. Present case highlights the simple mode of management with a successful outcome.

Keywords: cervical dysgenesis; imperforate hymen; transverse vaginal septum.

\section{INTRODUCTION}

Female reproductive tract abnormalities are generally encountered in $2 \%$ to $3 \%$ of women. ${ }^{1}$ Imperforate hymen is the most common obstructive defect, with a reported incidence varying from $1: 1000$ to $1: 16,000$ female births. Transverse vaginal septum is rarer with an incidence of $1: 21,000$ to $1: 72,000$ women and may lie on the upper, middle, or lower third of the vagina with a relative incidence of $46 \%, 35 \%$, and $19 \%$, respectively. Both these situations causes obstruction of the female genital tract, it becomes symptomatic during newborn period and infancy leading to mucocolpos, and more often after menarche resulting in haematocolpos and haematometra. Congenital cervical agenesis with or without vaginal agenesis is a rare Mullerian developmental disorder that occurs in one in every 80,000 to 100,000 births. $^{2}$

\section{CASE REPORT}

An 11 years old girl reported to the department of Pediatrics on fourth march 2012, with acute lower abdominal pain and pain during micturition since one day. Patient was apparently well two months back when she developed off and on pain in lower abdomen, with no radiation, mild in intensity, increased during micturition and relieved by medication. One day prior to admission, she developed severe pain in suprapubic and infraumbilical region with no radiation, continuous and severe in intensity, got aggravated during micturition and was not relieved by any medication. General examination was within normal limits. She had normal secondary sexual characteristic with normal development of the breast and pubic hairs (Tanner II stage). On abdominal examination, lower abdominal tenderness was present. Examination under anesthesia revealed the hymen to be replaced by a thin membrane like structure. On per rectal examination, vagina was felt all through its length, a bulky, tender $6 \mathrm{~cm} \times 6 \mathrm{~cm}$ tensely cystic mass above the vagina and anterior to the rectum was felt. A probable diagnosis of haematometra with imperforate hymen was made and was planned

Correspondence: Dr. Pratiksha Gupta, Department of Gynecology and Obstetrics, Post Graduate Institute of Medical Sciences and research, ESIC, Basaidarapur, New Delhi. Email: drpratiksha@gmail.com, Phone: +919871128703 
Pratiksha et al. Cervical Dysgenesis with Transverse Vaginal Septum with Imperforate Hymen in an 11 year old Girl Presenting...

for further investigations for definitive diagnosis. All hematological investigations were within normal limit. Transabdominal ultrasound revealed haematometra and, haematosalpinx with imperforate hymen. Magnetic Resonance Imaging (MRI) of pelvis and whole abdomen revealed a septum at proximal aspect of vagina, cervical dysgenesis with haematometra and right haematosalpinx (Figure 1).

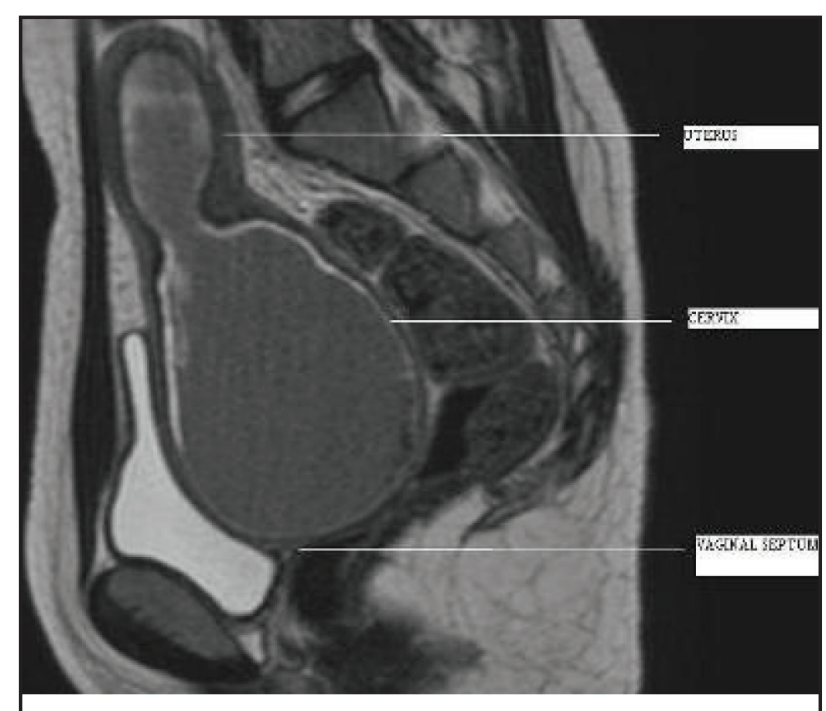

Figure 1. Prior to first surgery MRI film: uterus with haematometra, dysgenetic cervix, -which is ballooned up, non canalization of cervical os, and a transverse vaginal septum.

Surgery was planned. Imperforate hymen was incised, normal canalized vagina was visualized and a transverse vaginal septum was seen at the proximal end of vagina. Excision of transverse vaginal septum was done. Now a tensely cystic bluish brown uterus was seen, cervix was not visualized. Stab incision was given in lower part of uterus followed by dilatation by Hegar's dilator to reconstruct the cervix. After dilatation, a Foley's catheter was inserted through the opening and inflated with $30 \mathrm{ml}$ normal saline which was removed on $8^{\text {th }}$ post operative day. On $9^{\text {th }}$ day finger dilatation under local anesthesia done and she was discharged on next day. She reported to us on postoperative day 19 , the patient had again developed fusion of vaginal septum with haematocolpos. MRI Examination showed canalized lower vagina and a vaginal septum in upper two third of vagina and haematocolpos (Figure 2). On day 20 she developed high grade pyrexia with rigors, she was put on injection Imipenem. On day 21 purulent vaginal discharge started, pyrexia subsided. Under anesthesia, vaginal septum was again incised. Purulent material was drained, with suction irrigation. Indwelling catheter was introduced and the bulb was inflated. This was removed on post operative day four. Thorough irrigation of vagina was done daily and vaginal pack was inserted. Vaginal mould was inserted daily from day seven with estrogen cream, under all aseptic precautions. There were no post operative complications. Vagina got fully reepithelialized within two weeks. She resumed normal menstruation the next cycle (Figure 3 ).
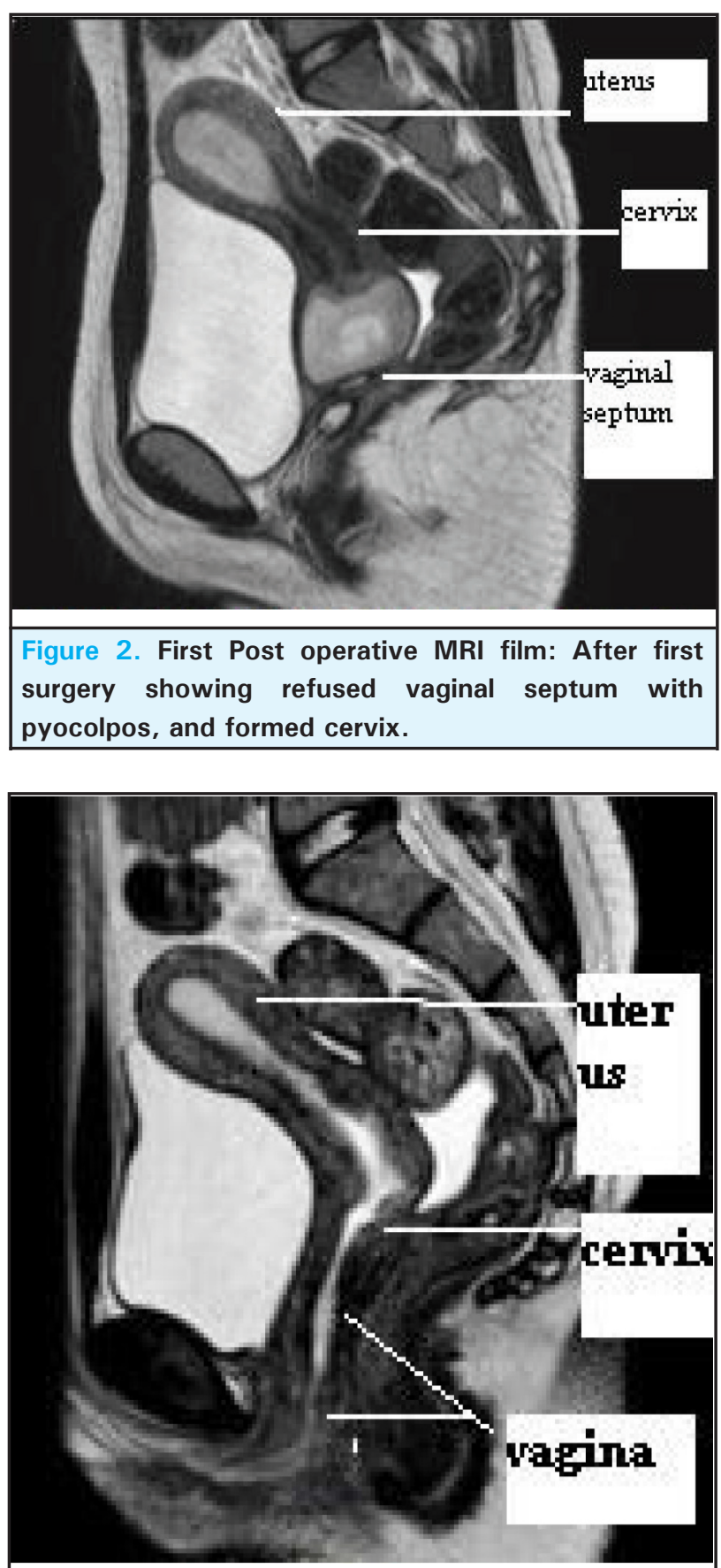

Figure 3. After Second Surgery MRI film: Normal uterus and normally formed cervix, and vagina. 


\section{DISCUSSION}

During fetal development, the Mullerian ducts represent the primordial components of the female reproductive system. They differentiate into the fallopian tubes; uterus, cervix, and the superior aspect of the vagina. ${ }^{3}$ The overall published data suggest a prevalence range of uterovaginal anomalies of around 1-6\%. ${ }^{4}$ Cervical agenesis has two basic anatomical types. First, the cervix is absent with narrow lower uterine segment and absent vagina. ${ }^{5}$ The second type is cervical dysgenesis, which is usually an obliterated cervix associated with a vagina of normal length. ${ }^{5}$ Embryologic failure of one or more Mullerian ducts results in cervical dysgenesis. ${ }^{6}$ Further, cervical dysgenesis consists of four subtypes: normal uterine fundus without cervix, presence of cervical body with obstruction to the cervical os, detached fragmented cervix with no connection to the uterine body, and attached obliterated cervix to the uterine body by a fibrous band of variable length and diameter. ${ }^{5}$ Transverse vaginal septum manifest usually around the age of menarche, with cyclical pain, of increasing intensity due to obstructed menstruation. ${ }^{7}$ Transverse vaginal septum is caused by a defect of vertical fusion of the Mullerian ducts during embryogenesis. ${ }^{8}$ It occurs in approximately $0.1 \%$ of live births and may be associated with other abnormalities. ${ }^{8}$ Diagnostic methods include hysterosalpingogram, transvaginal ultrasound, computed tomography, magnetic resonance imaging, laparoscopy, and hysteroscopy. Hysteroscopy can detect intrauterine adhesions and communication between the duplicated endometrial cavities. Magnetic resonance imaging has
$96-100 \%$ accuracy in classifying uterine anomalies, while transvaginal ultrasound has 85-92\%, and hysterosalpingography has $6-55 \% .^{9}$ Pelvic imaging with ultrasound was usually the first imaging procedure used due to its reproducibility and good sensitivity in exploring congenital defects although HSG has been the first method before the advent of ultrasound. ${ }^{10-13}$ $\mathrm{MRI}$ is also associated with a good sensitivity and specificity. Currently other imaging techniques are useful in the diagnosis of uterine anomalies. Tran's rectal ultrasound has been reported to help in de-fining the pelvic anatomy, which can be especially useful in young patients. ${ }^{14}$ Finally, three-dimensional ultrasound may be promising when conducted by experienced operators. ${ }^{15}$ The training of general practitioners and sonographers should be improved to increase the sensitivity of ultrasound examinations in general practice because Ultrasound diagnosis can avoid the need for laparoscopic investigation. For epethialization of vaginal mucosa, local estrogen cream is effective, skin graft can be avoided. Imperforate hymen is potentially accompanied by other female reproductive tract anomalies, suggesting a multifactorial etiology. Treatment should be chosen with the perspective of future fertility. This is the first case report with three anomalies in one patient and a successful outcome in the literature review, in Medline and Pubmed. It is an original case report of interest to all clinical specialty of medicine, as for example: acute abdomen will be encountered in General Surgery, Gastroenterology, General Medicine, Pediatrics, Gynecology so it has a broader clinical impact across more than one area of medicine.

\section{REFERENCES}

1. S.W. Gray, J.E. Skandalakis, B. Broecker. The female reproductive tract. In: J.E. Skandalakis, S.W. Gray, editors. Embryology for surgeons. Baltimore: Williams and Wilkins; 1994. p. 816-47.

2. Westerhout FC, Hodgman JE, Anderson GV et.al. Congenital hydrocolpos. Am J Obstet Gynecol. 1964;89:957-61.

3. Rock JA, Thompson JD. Telende's operative gynecology. Philadelphia: Lippincott-Raven; 1996. p. 704-6.

4. Rock JA, Zacur HA, Dlugi AM, Jones HW Jr, TeLinde RW. Pregnancy success following surgical correction of imperforate hymen and complete transverse vaginal septum. Obstet Gynecol. 1982 Apr;59(4):448-51.

5. Buttram VC Jr.Müllerian anomalies and their management. Fertil Steril. 1983 Aug;40(2):159-63.
6. Gholoum S, Puligandla PS, Hui T, Su W, Quiros E, Laberge JM. Management and outcome of patients with combined vaginal septum, bifid uterus, and ipsilateral renal agenesis (Herlyn-Werner-Wunderlich syndrome). J Pediatr Surg. 2006 May;41(5):987-92.

7. Sørensen S. Estimated prevalence of müllerian anomalies. Acta Obstet Gynecol Scand. 1988;67(5):441-5.

8. Zanetti E, Ferrari LR, Rossi G. Classification and radiographic features of uterine malformations: hysterosalpingographic study. Br J Radiol. 1978 Mar;51(603):161-70.

9. Rock JA, Breech LL. Surgery for anomalies of the mullerian ducts. In: Rock JA, Jones HW, editors. Telinde's operative gynecology. 10th ed. Philadelphia: Kluwer/Lippincott Williams and Wilkins; 2008. p. 539-84.

10. Acién P. Embryological observations on the female genital tract. Hum Reprod. 1992 Apr;7(4):437-45. 
11. Rock JA, Zacur HA, Dlugi AM, Jones HW Jr, TeLinde RW. Pregnancy success following surgical correction of imperforate hymen and complete transverse vaginal septum. Obstet Gynecol. 1982 Apr;59(4):448-51.

12. Joki-Erkkila MM, Heinonen PK. Presenting and long-term clinical implications and fecundity in females with obstructing vaginal malformations. J PediatAdolescGynecol. 2003;16:307-12.
13. Pui MH. Imaging diagnosis of congenital uterine malformation. Comput Med Imaging Graph. 2004;28:425-33.

14. Wu MH, Hsu CC, Huang KE. Detection of congenital mullerian duct anomalies using three dimensional ultrasound. J Clin Ultrasound. 1998;1:631-6

15. Woelfer B, Salim R, Banerjee S, Elson J, Regan L, Jurkovic D. Repro-ductive outcomes in women with congenital uterine anomalies detectedby three-dimensional ultrasound screening. Obstet Gynecol. 2001;98:1099-103. 